\title{
Memórias sobre o trabalho nos anos finais do Ensino Fundamental: o uso de documentos históricos em sala de aula*
}

\author{
Memories about work in the final years of elementary school: the use of historical \\ documents in the classroom
}

\begin{abstract}
Juliano Alves da Silva
Doutor em História pela Universidade Federal da Grande Dourados (UFGD) Professor de História do Programa de Ensino Integral (PEI) da Secretaria de Educação do Estado de São Paulo (SEDUC/SP) julianoasilva@prof.educacao.sp.gov.br
\end{abstract}

\begin{abstract}
Resumo: O presente artigo tem por objetivo apresentar uma contribuição acerca da construção do conhecimento histórico em sala de aula. Dessa forma, o objeto desta reflexão enuncia um conjunto de práticas realizadas por estudantes do Ensino Fundamental na Escola Estadual José Emygdio de Faria, na cidade de Jaci-SP, no ano letivo de 2014. As discussões sobre temporalidades históricas, memórias, o uso de fontes e escrita da História são, em certa medida, parte de muitas possibilidades para o Ensino de História diante do imediatismo e desvalorização da área enquanto campo de conhecimento científico. Pensar no Ensino de História, trouxe grandes desafios para o entendimento de sua percepção transformadora e, sobretudo, para os encantos de uma ciência comprometida com os fascínios da evolução dos seres humanos ao longo do tempo.
\end{abstract}

Palavras-chave: Ensino de História; memórias; ensino fundamental.

\begin{abstract}
This article aims to presente a contribution on the construction of historical knowledge in the classroom. Thus, the object of this reflection enunciates a set of practices carried out by elementary school students at the José Emygdio de Faria State School in the city of Jaci SP, in the 2014 school year. Discussions about historical temporalities, memory, the use of sources and the writing of history are, to a certain extent, part of many possibilities for teaching history in the face of the immediacy and devaluation of the area as a field of scientific knowledge. Thinking about Teaching History has brought great challenges to the understanding of its transformative perception and, above all, to the charms of a science committed to the fascinations of the evolution of human beings over time.
\end{abstract}

Keywords: History Teaching; memory; elementary School.

\footnotetext{
* Este artigo originou-se de uma proposta de trabalho sobre a utilização das fontes históricas em sala de aula na Escola Estadual José Emygdio de Faria na cidade de Jaci-SP, no segundo semestre do ano letivo de 2014. A proposta de estudo sobre o tema fez-se mediante a produção de conhecimento histórico de forma cooperativa, cujo foco central foi o trabalho em conjunto entre o professor da disciplina e os alunos de quatro turmas do mesmo ano do Ensino Fundamental.
} 


\section{Introdução}

O Ensino de História passou por transformações significativas, a partir do momento em que se modificou a forma de condução e elaboração do processo de produção do conhecimento histórico. Para diversos historiadores, a forma de narrar o passado tem a ver, em número e grau, com a maneira de trabalho com as fontes de pesquisa, o que permite não apenas pensar sobre a História de maneira epistemológica, mas questionar os caminhos possíveis para a produção do conhecimento histórico.

As novas formas de condução do processo de produção do conhecimento histórico refletiram, em maior ou menor grau, na produção historiográfica tendo dois pontos como referência: a própria narrativa histórica diante de sua legitimidade e o aparelhamento da pesquisa em si, a partir de diferentes correntes teóricas e tratamento dos diversos tipos de fontes.

O documento oficial, visão tradicional sobre a fonte histórica - tido como único suporte capaz de portar o sentido de verdade -, foi alvo de intensos questionamentos no início da escola dos annales, principalmente por Bloch e Febvre, deixando-o de ser divinizado como a própria Clio. Ao iniciarem o movimento dos annales ou, em uma leitura freudiana, ao ganharem liberdade intelectual de questionar seus mestres Langlois e Seignobos - como um filho que se liberta do jugo do próprio pai - Bloch e Febvre propuseram questionar a hierarquia do documento e o seu sentido absoluto.

O locus das discussões teórico-epistemológicas, de certa forma, abarcou uma série de consequências para as dimensões da História, tendo como ressonância diferentes possibilidades também no campo do trabalho em sala de aula. É possível ressaltar que, sem sombra de dúvidas, as novas perspectivas para o estudo da História transformaram as dinâmicas de aprendizagem no Ensino de História.

A discussão proposta no artigo trata dos desafios e perspectivas para o Ensino de História em sala de aula. Longe de propor uma análise profunda a respeito dessa temática, esta discussão visa levantar reflexões de cunho teórico e metodológico sobre o papel da História em sala de aula e parte do entendimento de um tema tão debatido pela historiografia brasileira e internacional: a escravidão no Brasil.

Para este trabalho, foram utilizados três tipos de documentos. São eles: 1) Diálogo entre os personagens de Machado de Assis. Escobar e Bentinho são personagens da obra 
de Machado de Assis e dialogam sobre os escravos da família deste; 2) Carta de alforria de Caetana Felicidade do Nascimento. 3) Foto de Militão, São Paulo, 1879.

Sem propor soluções ou modelos metodológicos para o tema, este artigo traz reflexões genuínas sobre o Ensino de História e a prática em sala de aula, em um universo caótico contraproducente que alimenta a exclusão. Portanto, nessas linhas traçadas com incompletude, aventuro-me em algumas reflexões realizadas pela dinâmica de análise das fontes históricas e o trabalho em sala de aula sem a pretensão, é claro, de esgotar o assunto e assumindo os riscos de não dar conta, com propriedade, de responder questões complexas sobre a epistemologia da História e o Ensino de História.

A partir de um viés etnográfico, este trabalho ganhou forma tendo como preceito os anseios e dúvidas diante do trabalho com alunos de quatro turmas de $9^{\circ} \mathrm{s}$ anos, sendo uma delas de Recuperação Intensiva $(\mathrm{RCI})^{1}$. Dessa forma, o trabalho etnográfico permitiu a construção do aporte para as discussões entre História e Memória agindo, assim, na própria dinâmica do texto, impregnado por um pressuposto dualístico o que, em certa medida, torna possível a concepção da própria História. Diante de tais complexidades, ao mesmo tempo que construo a narrativa sobre o passado, interpreto os fatos e reconstruome nesse mesmo passado, tendo como força vital o olhar do presente.

\section{Memórias de conflito}

Muitos historiadores, desde a revolução dos annales, assim caracterizada por Peter Burke em sua obra A Revolução Francesa da Historiografia, debruçaram-se em questões cruciais sobre a construção do conhecimento histórico. Diante do complexo sentido criado na relação entre Memória e História, diferentes vertentes historiográficas mostraram-se empenhadas em construir referências sólidas para o campo de atuação do historiador. No que diz respeito a prática historiográfica, muitas análises ofereceram novos fundamentos para a historiografia, bem como criaram debates polêmicos em torno do tema os quais ainda suscitam consensos e controvérsias.

\footnotetext{
${ }^{1}$ Nomenclatura técnica designada pela Secretaria de Educação do Estado de São Paulo (SEDUC-SP). O trabalho realizado com a turma de RCI teve por fundamento o Artigo 13 da Resolução SE 73, de 29-122014, que dispõe sobre a reorganização do Ensino Fundamental em Regime de Progressão Continuada e sobre os Mecanismos de Apoio Escolar aos alunos dos Ensinos Fundamental e Médio das escolas estaduais. Disponível http://siau.edunet.sp.gov.br/ItemLise/arquivos/ 7 em:
} 
Para Jacques Le Goff, ao analisar a Memória, é importante destacar que determinados aspectos como "o interesse, a afinidade e o desejo" garantem possibilidades de acesso aos acontecimentos que ajudaram a construir a identidade de um determinado povo (LE GOFF, 1992). Todavia, os aspectos referentes à memória podem trazer outras discussões como a falha proposital do ato de rememorar; uma imprecisão de sentido, quando a memória deixa-se falhar pelo direito ao esquecimento. Quanto a esse direito, Alessandro Portelli nos dá que a sua imprecisão de sentido faz parte, sobretudo, do não dito, e o silêncio em muitos casos se remete a construção psíquica do acontecimento (PORTELLI, 1997).

A transformação do cotidiano de qualquer indivíduo sofre com a insistência da permanência da continuidade histórica, traduzida em uma luta incessante do simbolismo contra a ruptura. Para Le Goff, mesmo a História contrapondo-se à Memória, elas se completam no sentido de gerenciar uma coexistência. Com base em seus estudos, é possível ampliar para a discussão sobre a oralidade como fonte de pesquisa para a história do tempo presente, uma vez que a história recente recebe um suporte essencial da História Oral. Para Le Goff, "[...] a passagem do oral para o escrito é muito importante, quer para a memória, quer para a história. Mas não devemos esquecer que a oralidade e escrita coexistem em geral nas sociedades, e esta coexistência é muito importante" (LE GOFF, 1992: 53). Nesse processo, a atividade intelectual é guiada pelo minucioso trabalho de busca dos indícios, como salienta Marc Bloch, e esses indícios podem permitir o entendimento dos lugares de memória e os tempos da história, a partir da produção do conhecimento histórico.

Ao analisar a oralidade e as memórias de alunos que participaram de atividades pedagógicas em 2014, foi possível compreender, de maneira sumária, as nuances da relação História e Memória.

A partir de atividades e entrevistas realizadas com os alunos Elias, Matheus, Letícia, Douglas, Laura, Nicole, Vitória, Davi, João Lucas e Laura percebeu-se que a relação entre História e Memória pode ser trabalhada na construção da narrativa histórica, tendo também como foco o trabalho de construção deste artigo, evidenciado por sua relação intrincada entre produção historiográfica e memorialista.

Primeiramente, gostaria de justificar a demora de escrita deste artigo. Desde o trabalho inicial, levantamento da problemática, captação dos recursos de análises, mensuração dos dados, conclusão e a escrita, foram seis anos. No entanto, sempre imaginei como seria o término desse artigo, a partir do primeiro momento em que a 
atividade foi desenvolvida. Inclusive, no tocante aos procedimentos teóricometodológicos e levantamento de hipóteses, a composição do quadro analítico aconteceu de imediato. Outras questões, tanto de cunho filosófico como existencial, foram sucedidas nas angústias pedagógicas. Portanto, não sei bem se consegui construir esse artigo, em se tratando das discussões levantadas e trabalhadas, ou se ele me construiu ao longo desses anos, revigorando minhas forças e atitudes em meio ao caos da educação.

Em muitos casos, somos assombrados pela vastidão dos desejos de um mundo diferente, em que a justiça e a solidariedade se façam sólidas e o simples término de uma atividade, como essa, trouxe questões existenciais gestadas com a demanda do trabalho pedagógico habitual, muito parecido, inclusive, com a massificação do trabalho industrial.

É só imaginar, por exemplo, a dinâmica da fábrica e de uma escola que perceberá a semelhança. O tempo triste da sirene, o intervalo, o controle do tempo para ir ao banheiro, a produção massificada e quantitativa de habilidades e conteúdos e, por fim, o horário de se livrar do fardo. Assim, marca-se nos porões das paredes pedagógicas mais um dia; mais uma sexta-feira; mais um mês. Em tempos de pandemia, tudo fica ainda pior, diante das incertezas que trouxe o ano de 2021 com a abertura, indiscriminada, das escolas sem condições de garantia do oferecimento de protocolos essenciais por causa da ausência de um corpo de funcionários. Sob fogo cruzado, o trabalho pedagógico acontece (ANTUNES, 2020) e atende mais aspectos econômicos do que educacionais.

Sem falar, é claro, do nível tecnológico de grande parte das escolas em São Paulo e no Brasil afora, mais similar às técnicas dos Neanderthalensis, quando descreviam suas atividades nas cavernas. Na sala de aula, espera-se um milagre, uma pedra escrevinhando sobre outra pedra e nós, professores, contraditoriamente, contribuindo com a formação de uma sociedade tecnológica. Dessa forma, uma rocha sedimentar porosa (giz), torna-se o elo "sagrado" entre a parede cimentada (com a cor preta) e o conhecimento científico.

Ensinar História, nessas circunstâncias, é também lutar contra um sistema de ensino sucateado e que, de fato, é mais burocrático do que transformador. É evidenciar, por outro lado, o avanço da cultura neoliberal que transforma servidores públicos em serviçais privados. Portanto, antes de concluir este trabalho, o cotidiano escolar empurrava-me para o questionamento do próprio sentido de estar ali em uma sociedade que sobrevive, cotidianamente, com as mazelas da exploração do homem pelo homem. 
Como ensinar História para uma sociedade que prefere o esquecimento? Como ensinar, crianças pobres ou de periferias, em um país em que o seu capital cultural ${ }^{2}$ é tão inferior em relação aos países desenvolvidos e achar que isso é normal? O que estamos querendo reforçar com o comportamento de acolhimento socioemocional desses alunos, ao invés do trabalho educacional de fato?

Obviamente, é complexo recorrer às práticas culturais eruditas, neste artigo, sobretudo para examinar o Ensino de História e a operacionalidade de um conceito como o de Bourdieu: capital cultural. A despeito da seriedade dos espaços desestruturados, principalmente por questões de ordem econômica e/ou de natureza geopolítica, que reserva aos grupos sociais menos favorecidos desse país a simples indiferença, é preciso também pensar nas possibilidades de resolução desses problemas. Problemas esses que, sem sombra de dúvidas, seriam sanados com um pouco mais de vontade política.

Uma das consequências nefastas da desvalorização do ensino, principalmente, nas esferas governamentais, está no hábito exclusivo de incentivar a inteligência lógicomatemática e Língua Portuguesa, como se fosse possível definir o desempenho dos alunos apenas nessas áreas. O SARESP ${ }^{3}$ é o exemplo mais gritante, pois os alunos são avaliados mais pelo que eles não são, em detrimento de uma avaliação que visa entender as múltiplas inteligências (GARDNER, 1994).

Segundo Eric Hobsbawm, a função do historiador é "lembrar aquilo que os outros esquecem, ou querem esquecer” (HOBSBAWM, 2007: 9). Afirmação reveladora de quem combateu pensamentos imediatistas, cuja ausência de senso crítico - perigosamente limitado e conservador - esconde interesses diante do triunfo catastrófico da ignorância dos fatos que ocorreram com a humanidade. Pouco provável por descuido, mais por intenções obscuras.

Diferentemente de um sistema de ensino que valoriza a fluidez, o fluxo acima de tudo - falo com propriedade por estar oito anos em uma instituição governamental e viver sistematicamente esse pesadelo -, pensar nessas questões trouxe-me outros elementos para o cenário da produção dessa atividade. Assim sendo, o que por hora parece demora,

\footnotetext{
${ }^{2}$ A noção de Capital Cultural pode ser entendida a partir de Bourdieu, quando decodifica: Los três estados del capital cultural.

3 O Sistema de Avaliação de Rendimento Escolar do Estado de São Paulo (Saresp) é aplicado pela Secretaria da Educação do Estado de São Paulo com a finalidade de produzir um diagnóstico da situação da escolaridade básica paulista, visando orientar os gestores do ensino no monitoramento das políticas voltadas para a melhoria da qualidade educacional. Disponível em: https://www.educacao.sp.gov.br/saresp.
} 
na verdade acabou sendo o tempo de maturação para pensar nos dissabores da educação no Brasil e, mais especificamente, em São Paulo.

Minhas impressões a respeito da educação no Estado de São Paulo, tendo trabalhado anteriormente em Mato Grosso e Mato Grosso do Sul - como um cidadão e funcionário público -, é de que há muito por fazer. Mas nem por isso temos o direito de esmorecer, pois os desafios da educação no Brasil e, sobretudo, o Ensino de História, marcam novas trincheiras no sentido de buscar ações eficazes para um mundo em que os jovens possam exercer a justiça, a autonomia e solidariedade.

Acredito que diante de tanta gente sem ter, se quer, o que comer, a educação pode ser vista como privilégio. Mesmo sendo a obrigatoriedade física garantida por lei uma realidade, muitos corpos físicos não conseguem uma conexão pura entre seus espíritos, em alguns casos, aprisionados em outros universos: como a fome, discriminação, a baixa renda e problemas de diferentes naturezas que afetam, principalmente, as classes empobrecidas pela sociedade capitalista. Portanto, na sociedade do capital, educação, trabalho e recursos são privilégios de quem tem "bucho cheio", de solidariedade são marcas registradas da espécie humana. Para além de uma sociedade que desvaloriza o indivíduo e sua multiplicidade, é importante evitar a lamentável ditadura da praticidade, do tecnicismo e da condolência cognitiva.

Neste momento, portanto, volto-me à escrita não por uma obrigatoriedade de conclusão de qualquer coisa. Não só por isso, mas também por isso. O vazio da incompletude é desolador. $\mathrm{O}$ que me fez perceber que entre o preto e o branco, existem áreas cinzas das quais não se consegue fugir da obliquidade.

Espero ansiosamente que assim como "o fogo também abriu a primeira brecha significativa entre o homem e os outros animais" (HARARI: 192-193), as reflexões acadêmicas possam exercer o seu papel social.

Utilizo neste texto a liberdade, como Fernando Pessoa, de "Não cumprir um dever" ${ }^{\prime 5}$ para poder sobreviver à medida que sonhar, com um mundo justo e igualitário, é sonhar, consequentemente, com o futuro das nossas crianças.

\footnotetext{
${ }^{4}$ Expressão mais comum em Minas Gerais, usadas tanto pelos escravos quanto por seus exploradores, evidentemente que com outra conotação da que se usa hoje. Atualmente, significando estar bem alimentado, de barriga cheia, na época significavam a obrigação que os escravos que trabalhavam nas minas de ouro possuíam de preencher com ouro um buraco na parede, conhecido como "bucho", para só então receber sua tigela de comida. Disponível em: https://www.geledes.org.br/9-expressoes-populares-com-origensligadas-escravidao-e-voce-nem-imaginava/. 1 10R

${ }^{5}$ Fernando Pessoa nasceu em Lisboa, Portugal, em 1888. Em 1914, escreveu os primeiros poemas de seus principais heterônimos: Alberto Caeiro, Álvaro de Campos e Ricardo Reis. É um dos maiores escritores
} 
O mundo do pensamento, dos desejos e crenças é, por definição, um universo complexo. Pensar que a Educação pode ser a porta de entrada para a salvação social e material é, por consequência, acreditar que a nossa sociedade tem a capacidade de fazer diferente do modo como se comporta na atualidade, deixando de lado a ganância, o autoritarismo e a insensibilidade.

\section{Re/Construção do conhecimento histórico: entre a Escravidão e a liberdade no Brasil imperial}

Do ponto de vista da psicologia cognitiva piagetiana (PIAGET, 1970), esse tema foi desenvolvido a partir de uma sequência didática com oito aulas, tendo como foco a análise da aprendizagem dos alunos de quatro turmas do $9^{\circ}$ ano do Ensino Fundamental.

Os suportes e abordagens diferenciadas, do ponto de vista metodológico, contribuíram para o alargamento de habilidades intertextuais e interdisciplinares, o mote de qualquer desenvolvimento das competências leitora e escritora.

A sequência didática foi dividida em quatro etapas: introdução ao tema, no que diz respeito aos conceitos históricos; análise das diferentes fontes na construção do conhecimento histórico; produção textual em forma de avaliação e devolutiva de todo o processo.

As fontes analisadas pelos alunos tiveram a função de dialogar com o contexto histórico proposto para o estudo: a escravidão no Brasil Imperial em seu viés multifacetado. A relação entre o contexto histórico e as fontes estudadas - em diferentes dimensões - permitiu uma maior compreensão do processo histórico em curso e a multiplicidade das relações sociais estabelecidas em meio a afirmação e aos questionamentos do sistema escravocrata.

De acordo com Rafael Ruiz, o Ensino de História pode trazer reflexões importantes para a prática historiográfica. Para o autor: "Ensinar a edificar o próprio ponto de vista histórico significa ensinar a construir conceitos e aplicá-los diante das variadas situações" (RUIZ, 2007: 75).

\footnotetext{
da literatura em língua portuguesa e certamente ocupa lugar de destaque também na literatura mundial. Fonte disponível em: https://brasilescola.uol.com.br/literatura/os-melhores-poemas-fernando-pessoa.htm. Acesso em 13/07/2020.
} 
Utilizar documentos históricos para o trabalho em sala de aula, ofereceu bases para pensar como se desenhou a questão da escravidão nesse período, permitindo assim esboçar a forma como o negro era visto e tratado pela sociedade imperial. Nesse sentido, as estratégias para o trabalho deram-se em torno da ideia de participação mútua e socialização do processo de ensino-aprendizagem.

Ao abordar o sistema de linguagem das fontes históricas, bem como as possibilidades oferecidas pelas informações contidas nelas, foi possível adentrar em um universo interdisciplinar. Para Marc Bloch, as contribuições metodológicas das diferentes áreas das Ciências Humanas fluem com profusão, o que permite ao historiador um melhor recorte teórico-metodológico para compreender a relação entre passado e presente, pois “[...] a incompreensão do presente nasce fatalmente da ignorância do passado. Mas talvez não seja menos vão esgotar-se em compreender o passado se nada se sabe do presente" (BLOCH, 2001).

A produção e socialização do conhecimento histórico em sala de aula, tornou-se uma ferramenta indispensável ao processo de ensino-aprendizagem. Como pontua Libâneo, este ato deve se dar de maneira em que o aluno possa se perceber enquanto sujeito produtor de conhecimento, nos seus mais diferentes níveis de habilidades cognitivas, permitindo a possibilidade de independência de pensamento (LIBÂNEO, 1994: 79). O autor nos mostra que a educação é constituída a partir de uma troca incessante de saberes. Para além de um sistema de ensino calcado na proposta que valoriza apenas o conteúdo, essa relação de troca precisa gerar um entendimento de questões complexas sobre o conhecimento escolar. O aluno, nessa perspectiva, não é apenas o produto do sistema educacional, mas também o produtor das relações em que o ser humano estabelece com o saber escolar. Buscar uma prática que ultrapasse o habitual pragmatismo educacional - em que pese a sociedade na qual impera o imediatismo da informação esvaziada de conteúdo do mundo globalizante -, é não limitar o processo educacional a mera transposição didática ${ }^{6}$ e avançar na autonomia do sujeito. Portanto, é necessário indagar qual o tipo de ensino deveríamos oferecer para a sociedade. Ou

\footnotetext{
${ }^{6}$ O conceito de transposição didática, segundo Circe Bittencourt (2004), toma o saber escolar como decorrente de sua ciência de referência, então, dependente das produções acadêmicas. Deste modo, "a escola é o lugar de recepção e de reprodução do conhecimento externo, variando sua eficácia pela maior ou menor capacidade de transpô-lo e reproduzi-lo adequadamente" (BITTENCOURT, 2004: 37). Segundo a autora, será pela mediação com a noosfera escolar e pela capacidade didática do professor em transpor esse conhecimento, que dependerá a eficácia do ensino. Este apresenta a disciplina escolar como um conhecimento de "segunda classe", havendo uma enorme hierarquização entre a disciplina acadêmica e a escolar. BITTENCOURT, Maria Circe Fernandes (2004). Ensino de História: fundamentos e métodos. São Paulo: Cortez.
} 
melhor, podemos mudar essa pergunta: as instituições de ensino estão realmente preocupadas com a qualidade da formação dos indivíduos? Essa educação é verdadeiramente um meio de transformação social, ou apenas a transposição das concepções de mercado?

Mézáros aponta algumas soluções para tais questionamentos, visto que a centralidade de sua prática educacional reside no fator que impera a eliminação das desigualdades sociais, em uma educação para além do capital (MÉZÁROS, 2005).

As discussões apresentadas por Circe Bittencourt (BITTENCOURT, 1993), sobre a transposição didática, chamam a atenção para pensar nas limitações de uma prática escolar - voltada ao Ensino de História, sobretudo por ser seu objeto de estudo -, desvinculada de uma certa autonomia na produção de conhecimento histórico.

É necessário, portanto, questionar os pressupostos da proposta de transposição didática, colocando em evidência o processo de construção da disciplina escolar como um movimento dinâmico e não como saberes sobrepostos. Longe de formar pequenos historiadores, Bittencourt salienta a necessidade de uma iniciação ao mundo historiográfico a partir da percepção dos alunos frente às discussões propostas pelos livros didáticos, assim como os professores de Química e Ciências o fazem diante de seus laboratórios.

A instituição escolar não possui a mesma estrutura, política, econômica, social e cultural das instituições universitárias, em termos de produção de conhecimento científico. Mesmo as "escolas modelo" no estado de São Paulo, como as do Programa de Ensino Integral (PEIs), ainda possuem uma estrutura arcaica, mais burocrática do que inovadoras. Nem por isso, a potencialidade das demandas das instituições escolares, deixam ausentes a dinâmica da construção de saberes. Em outras palavras, a escola também produz conhecimento, quem sabe pouco inovador, no sentido da produção intelectual universitária. Porém, a partir de sua especificidade e seu nível de intervenção na sociedade, a instituição escolar possui um capital social magnífico. Isso só é percebido quando os alunos passam a gerenciar a sua autonomia diante da leitura que fazem do mundo (FREIRE, 2004). Tal leitura Freiriana, em sua complexidade, remete-se ao fato de que: "Ninguém educa ninguém, ninguém educa a si mesmo, os homens educam-se entre si, mediatizados pelo mundo" (FREIRE, 1981: 81).

Tal perspectiva, de certa forma, tem por objetivo a descolonização de um pensamento europeizado e voltado apenas para a competição e supremacia do conhecimento científico diante de uma acumulação intelectual esnobe e sem sentido. 
Quijano, ao apontar a modernidade europeia como forma de existência mais avançada e, paradoxalmente, a mais normal de todas as formas de existência (QUIJANO, 2005), constata que a descolonização do pensamento pode ser a saída frente aos comportamentos padronizados. Quando o assunto se remete ao modelo de Ensino no século XXI - muito próximo ao modelo do século XIX - não se deve naturalizar comportamentos que limitam as possibilidades, atribuindo historicidade atemporal a determinadas práticas. Por isso, uma educação libertadora e carregada de sentido, tem por função uma aprendizagem significativa.

\section{Análise das fontes}

A primeira fonte analisada foi uma parte da obra literária de Machado de Assis. Após a introdução com aspectos gerais sobre o autor e a sua importância ao universo da Literatura, os educandos não compreenderam a proposta de análise histórica. Acreditavam na impossibilidade de analisar uma obra literária de cunho ficcional. O desafio, nesse momento, foi colocar em prática a noção teórica sobre as diferentes fontes de pesquisa em História.

Para os alunos, existia uma complexidade no entendimento de que a Literatura e a História, em muitos sentidos, bebem no mesmo copo (contexto social, fontes, personagens) e alimentam-se dos mesmos preceitos: a construção da narrativa.

História e Literatura envolvem-se com as temáticas de maneira em que suas dimensões não são radicalmente separáveis, mas acabam por se diferenciarem em seus objetivos: a História, como diria Marc Bloch, tem por finalidade a explicação dos fatos e atividades humanas ocorridas ao longo do tempo, um aspecto não utilizado na análise literária, calcada na construção de uma narrativa ficcional. O universo literário pode ser criado a partir dos efeitos de realidade, sem o comprometimento com a representação de uma realidade objetiva. Nem por isso, devemos ignorar a Literatura como fonte de pesquisa. Pra José Matoso: “A apreensão do real em todas as facetas implica que se ponham em jogo todas as faculdades de observação, não apenas as racionais, mas também as volitivas [...]" (MATOSO, 1988: 18). 
Se a Literatura é pouco precisa, em termos de realidade objetiva, a História não se comporta muito diferente, pois está alicerçada em representações. Segundo Chartier ${ }^{7}$, tais representações não podem interferir no sentido da apreensão do real, pura e simplesmente, como se de fato o historiador pudesse "inventar" suas histórias. Seu trabalho, assim como as diferentes ciências, é analisar, mensurar e evidenciar os fatos, resguardando o compromisso com a representação da realidade histórica. Nesse sentido, é evidente que a História é uma representação do passado, articulada a partir de pressupostos teórico-metodológicos, sobretudo em vista de seu caráter subjetivo e sua estrutura de linguagem. No entanto, o que está em jogo é a condição em que se encontra o historiador diante das questões que se remetem a sua própria prática. $\mathrm{O}$ respeito à metodologia empregada é o principal fator, pois para Paul Ricoeur (RICOUER, 2007: 143-301), deve estar calcada em três fases - semelhantes as quais propõe Certeau em sua Operação historiográfica (DE CERTEAU, 1982: 13-119). São elas: a fase documental que vai da declaração de testemunhos (em suas múltiplas dimensões), à composição dos arquivos, juntamente com a prova documental e demarcação epistemológica. Em seguida, a fase explicativa/compreensiva que exprime a recusa da oposição de ideias e fatos entre explicação e compreensão. E por último a fase representativa, em forma literária, ou escrita do discurso narrativo.

Para Rafael Ruiz, "Podemos trabalhar os diferentes modelos históricos através de um documento ou de um texto literário clássico.” “[...] tanto um texto de Tucídides, para mostrar a "História, mestra da vida", como um texto do A vida e as estranhas aventuras de Robinson Crusoé, de Daniel Defoe" (RUIZ, 2007: 78).

O que também chama a atenção é o fator de percepção sobre as diferentes realidades, tanto literária, quanto histórica.

Cerca de $60 \%$ dos alunos conseguiram entender a proposta de análise do documento. Outros nem tanto, principalmente pela questão intrínseca ao fato de que a História "fabrica" acontecimentos. Como ela poderia ser diferente da Literatura que também "fabrica" suas histórias? Nas palavras de um dos alunos: "como vou acreditar no que esse cara escreveu?". "Por que eu preciso saber da vida dos outros?” (Elias, aluno do $9^{\circ}$ ano C da Escola Estadual José Emygdio de Faria Doutor, do município de Jaci-SP, sala de RCI - Recuperação Intensiva).

\footnotetext{
${ }^{7}$ Texto originalmente apresentado em conferência na cidade de Barcelona e gentilmente disponibilizado por Roger Chartier para a consulta dos professores e alunos da Graduação e Pós-Graduação em História da universidade Federal da Grande Dourados (UFGD).
} 
De acordo com Ana Monteiro, essas perguntas são frequentes e despertam a falta de sentido que, de maneira geral, creditam ao estudo da História. Por isso, a autora analisa a falta de disciplina nas aulas e o desinteresse como resultado dos frequentes questionamentos (MONTEIRO, 2001).

Logo após esse questionamento, o coro do $9^{\circ}$ ano $\mathrm{C}$, em uníssono, entoou a defesa da não realização da atividade. Por ser uma turma de RCI, com índices elevados de defasagens das mais diversas, o diálogo era complexo. Foi preciso convencê-los a entrar no jogo. As outras turmas não ofereceram resistência, mas desconfiavam da atividade por conta das entrevistas e relatórios.

Com muita desconfiança, os alunos decidiram realizar o trabalho de análise das fontes. Mas a pergunta ainda persiste seis anos depois e incomoda o mais perspicaz historiador. Talvez para um público com conhecimento histórico mais refinado, tais trivialidades são fáceis de serem respondidas teórica e metodologicamente. Mas o grande triunfo da História está na revelação das aventuras da humanidade - como o ser humano se comportou durante milhares de anos -, de modo que tenha condições de expressar aos eruditos e às crianças, aos conhecedores e não conhecedores, como é belo o estudo e a investigação do passado da humanidade (BLOCH, 2001).

O primeiro documento, a seguir, evidencia o contexto e as relações sociais durante o Brasil Imperial. Diante do exposto, percebe-se as características de tal momento da História da sociedade brasileira.

Documento 1: Diálogo entre os personagens de Machado de Assis:

Estávamos na horta da minha casa, e o preto andava em serviço; chegou-se a nós e esperou.

- É casado, disse eu para Escobar. Maria onde está?

- Está socando milho, sim, senhor.

- Você ainda se lembra da roça, Tomás?

- Alembra, sim, senhor.

- Bem, vá-se embora.

Mostrei outro, mais outro, e ainda outro, este Pedro, aquele José, aquele outro Damião...

- Todas as letras do alfabeto, interrompeu Escobar.

Com efeito, eram diferentes letras, e só então reparei nisto; apontei ainda outros escravos, alguns com os mesmos nomes, distinguindo-se por um 
apelido, ou da pessoa, como João Fulo, Maria Gorda, ou de nação como Pedro Benguela, Antônio Moçambique...

- E estão todos aqui em casa? - perguntou ele.

- Não, alguns andam ganhando na rua, outros estão alugados. Não era possível ter todos em casa. Nem são todos os da roça; a maior parte ficou lá.

- O que me admira é que D. Glória se acostumasse logo a viver em casa da cidade, onde tudo é apertado; a de lá é naturalmente grande.

- Não sei, mas parece. Mamãe tem outras casas maiores que esta; diz porém que há de morrer aqui. As outras estão alugadas. Algumas são bem grandes, como a da Rua da Quitanda [...] (ASSIS, 1991: 145).

É interessante perceber que a utilização da fonte como ferramenta de construção do conhecimento histórico, permite ir além da problematização do livro didático. Para a aluna Vitória, a dimensão da produção da atividade estava ligada ao fardo de estar em uma sala com tantos problemas. Portanto, de início não se empenhou em sua realização. Aos poucos, quando percebeu um maior empenho da turma, foi entrando no ritmo. Sua resistência e seus questionamentos, genuínos também da idade, mostravam um pouco da ausência de entendimento crítico sobre a função da História. A todo momento, seu questionamento era "O que eu vou fazer com História? O que vai servir na minha vida?" (Vitória, aluna do $9^{\circ}$ ano $\mathrm{C}$ da Escola Estadual José Emygdio de Faria Doutor, do município de Jaci-SP, sala de RCI - Recuperação Intensiva).

O trecho do diálogo entre os dois personagens de Machado de Assis, mostrou que além do trabalho praticado costumeiramente: o da roça e da casa, uma das formas de escravização, o escravo de ganho, era um tanto quanto complexa. Tal leitura remete-nos à função do escravo de ganho (MACHADO, 2004) que era, em certa medida, ser alugado e/ou vender produtos nas ruas das cidades para poder gerar lucro para seus senhores e senhoras. Em alguns casos, para abater um determinado valor das vendas no preço de sua alforria. Dessa forma, diante da esperança de quitação do valor de sua dívida gerada com a escravidão, o escravizado sonhava, cotidianamente, com a possibilidade de viver uma vida livre.

Circe Bittencourt, em seus estudos sobre o uso do livro didático em sala de aula, evidencia que o material não pode ser o único caminho (BITTENCOURT, 1990). Isso tem a ver, entre outras coisas, com a transformação do livro didático em um dos recursos possíveis para os estudantes, como tantos outros. A autora discute a não necessidade do 
interesse de formar pequenos historiadores, mas se torna necessário - em um mundo cada vez mais imediatista -, que os alunos saibam, na prática, como se analisa e se constrói um texto histórico, ou simplesmente um texto.

Para Schmidt e Cainelli, o livro didático deve ser visto como um portal de possibilidades, como um instrumento fundamental para o desenvolvimento do conhecimento e "como parte articulada e articuladora da relação entre professor, aluno e conhecimento histórico" (SCHMIDT e CAINELLI, 2009: 172). Nesta articulação, o professor necessita de um senso crítico em relação ao processo de produção historiográfica.

O livro didático, segundo Bittencourt, é um instrumento pedagógico, ou seja, o lugar existente entre o conhecimento escolar e a possibilidade de sua subversão. Para SCHMIDT e CAINELLI, o livro não transmite apenas conhecimento científico, mas também valores culturais, por isso a necessidade de uma visão crítica.

O diálogo entre as personagens, permitiu aos alunos refletirem sobre toda estrutura da escravidão, tendo como princípio três eixos: a) introdução do tema, uma forma de entender questão da escravidão e suas consequências; b) analisar a forma como Literatura e História dialogam; c) entender os elementos que permitiram pensar sobre as variadas formas de resistência praticada pelos escravos, sem contar que tais discussões geraram um entendimento das possibilidades que os escravos criavam para a busca da liberdade. Nesse sentido, Rafael Ruiz concorda que: "Se, conforme dizia Hartog, a forma mais acertada para construir o próprio ponto de vista seria adotar uma abordagem comparativa, poderíamos tentar encontrar uma nova fonte de análise e de trabalho a partir da Literatura" (RUIZ, 2007: 78).

No segundo documento, a discussão tornou-se um pouco mais complexa para os alunos. O tipo de informação que consta na carta de alforria demonstra que o escravo poderia comprar sua liberdade através do trabalho duro. Assim sendo, no primeiro documento, a possibilidade de compra da alforria aparece nas entrelinhas, tendo como fundamento as análises de autores que se dedicaram, de maneira geral, a essa temática ${ }^{8}$.

\footnotetext{
${ }^{8}$ Ler: ARRUDA, José Jobson de Andrade (1988). Linhagens historiográficas contemporâneas por uma nova síntese histórica. Economia e Sociedade, Campinas, (10): 175-191, jun.; ARRUDA, José Jobson de Andrade (1980). O Brasil no comércio colonial. São Paulo: Ática; AZEVEDO, Célia Maria Marinho (1988). Batismo da liberdade: os abolicionistas e o destino do negro. História: questões e Debates, v. 16: 38-65. AZEVEDO, Célia Maria Marinho (1987). Onda negra medo branco. O negro no imaginário das elites - século XIX. Rio de Janeiro: Paz e Terra.
} 
Mas com o estudo dessa carta de alforria, os alunos tiveram a oportunidade de analisar tal universo.

Em alguns casos, chegaram à conclusão de que a alforria fosse melhor dessa forma em relação ao momento em que essa possibilidade nem existia, porém o dono estava correto em cobrar o valor, pois ele não poderia ficar com o prejuízo. Obviamente, o olhar impregnado do presente, em que tudo tem um valor no mundo das coisas, tal afirmação parece até desumana.

Nos escritos de outro aluno, Douglas, por exemplo, percebe-se essa linha de raciocínio. O materialismo doentio da nossa sociedade pode ser ofuscante e limitador, trazendo à tona pensamentos rasos e, de certa forma, acríticos. Um aluno pardo, empobrecido pela ganância do capital, posicionou-se em diferentes momentos favorável ao senhor: "os neguim tinham que pagar porque o patrão não poderia ter prejuízo".9

No século XXI, é preciso pensar em projetos de sociedade para a eliminação dos resquícios de um pensamento racista e materialista. Um bom devaneio, seria pensar: se o filósofo Platão (2000) vivesse no século XXI, o que diria da nossa sociedade? Que a humanidade, sem saber, prendeu-se nas cavernas? Que nossas mentes criaram as nossas próprias cavernas? Ou que criamos cavernas para aprisionarmos a humanidade?

$\mathrm{Na}$ análise da fonte documental, a carta de alforria ganhou um espaço de inquietações e críticas. Na realização da leitura, foi possível perceber diferentes nuances, dos olhares mais atentos aos indiferentes.

Documento 2: Caetana Felicidade do Nascimento; parda/mulata; Sr. Guilhermina Henriqueta de Magalhães; dt. reg. 11-09-35 (Livro 1, p. 76r). Desc.: A carta foi concedida mediante pagamento de 600\$, pelo Tenente Antônio Barcelo, sendo 550\$ à vista e o restante 50\$ em 2 meses, "preço que por sua senhora foi arbitrado para ter sua liberdade, com a única condição da dita parda Caetana o acompanhar enquanto ele libertador viva, tendo em consideração seu estado enfermisso, e sua avançada idade para the dar o necessário tratamento, e quando não cumpra esta cláusula ficar sua liberdade sem efeito (RIO GRANDE DO SUL; SECRETARIA DA ADMINISTRAÇÃO E DOS RECURSOS HUMANOS; DEPARTAMENTO DE ARQUIVO PÚBLICO. Documentos da escravidão: catálogo seletivo de cartas de liberdade. Acervo dos tabelionatos do interior do Rio Grande do Sul.

\footnotetext{
${ }^{9}$ Aluno do $9^{\circ}$ ano C, sala de RCI, da Escola Estadual José Emygdio de Faria Doutor, do município de JaciSP.
} 
Porto Alegre: CORAG, 2006. Livros Notariais de Transmissões e Notas Livro 1 - 1831 a 1846: 19).

Esta carta de alforria permitiu analisar a forma como os escravos eram submetidos ao sitema escravocrata. Diante disso, o trabalho foi organizado no sistema de agrupamentos de, no máximo, três alunos. Essa estratégia didática serviu para que os alunos pudessem discutir ideias a respeito do tema e chegar a possíveis conclusões.

Em um segundo momento, as salas tiveram o tempo para o debate, direcionado para os seguintes temas: 1) a possibilidade de trabalhar com um documento que serviu de base para a organização social do Império e o regime escravocrata; 2) a relação entre as propostas do regime escravista e a opressão sofrida pela população negra; 3) como foi reforçada o estabelecimento da política escravocrata e a permanência do racismo.

Os alunos, de maneira geral, construíram conhecimento sobre o tema e sua relação com sistema escravocrata do regime imperial. Em muitos casos, o maior questionamento foi a relação direta do tema com a vida cotidiana, a partir de sua interface com o preconceito racial ainda existente no Brasil.

Em um dos escritos de conclusão de atividade, chegou-se a questionar a validade de discussões desse porte, pois muitos já sabiam a respeito da necessidade de não discriminar as pessoas negras. O grupo número 3, das alunas Vitória, Nicole e Laura ${ }^{10}$, chegaram a alegar que "existe a possibiliade de punição judicial para os crimes de racismos". O que não ficou claro para os alunos, até o presente momento, de um modo geral, foi o fato de que o estudo da escravidão, assim como difentes temas para História, permite entender as transformações sociais entre continuidades e rupturas. Parace contraditório, mas no início da atividade os alunos não enxergavam sentido na História, mas ao relacioná-la como presente, com o racismo, por exemplo, conseguiram avaliar um outro horizonte.

A mesma atividade foi realizada em outras salas do mesmo ano. O grupo 2 da sala $9^{\circ} \mathrm{D}$ trouxe reflexões mais complexas a respeito do assunto. Tais reflexões permitiram uma análise comparativa entre a forma de abordagem e os resultados. As alunas Geovana, Larissa e Maria Eduarda ${ }^{11}$, chegaram a conclusão de que a História tem a capacidade de transformar olhares sobre as coisas que não são tão naturais em nossa sociedade.

\footnotetext{
${ }^{10}$ Alunas do $9^{\circ}$ ano C, sala de RCI, da Escola Estadual José Emygdio de Faria Doutor, do município de Jaci-SP

${ }^{11}$ Alunas do $9^{\circ}$ ano D da Escola Estadual José Emygdio de Faria Doutor, do município de Jaci-SP. 
Chegaram a conclusão de que "o racismo é tão cruel quanto foi a escravidão e que o brasileiro ainda pode mudar isso".

Para Hobsbawm o "calcanhar de Aquiles", da sociedade contemporânea, está no imediatismo calcado na desvalorização das experiências históricas. O grande desafio é como fazer com que o Ensino de História conceda um espaço capaz de quebrar as amarras do imediatismo e também como carregar de sentido a prática educativa, para além do fracasso escolar.

Sem dúvida alguma, o fracasso escolar é um problema grave que convive com a realidade social e pedagógica brasileira há muitos anos, em alguns casos, por ineficiência da gestão pública e, em outros, como projeto político fruto do descaso e da pauta neoliberal. Algumas estatísticas apontaram o período da infância como o mais complexo no que diz respeito a esse assunto. Para Cecilia Azevedo Lima Collares, em seu trabalho Ajudando a Desmistificar o Fracasso Escolar, essas questões assombram a prática educativa (COLLARES, 1982).

$\mathrm{Na}$ análise do próximo documento, a atividade ganhou um sentido mais prático, por força de se estudar uma imagem.

A fotografia enquanto fonte histórica, permitiu analisar a imagem não como um acontecimento, ou como uma verdade absoluta. Aliás, a bem da verdade, nenhuma fonte histórica tem esse poder. A fotografia em si, ou outro documento qualquer, não representam a veracidade dos fatos, ou seja, a forma literal da História. Nesse sentido, é importante analisar a forma como a fotografia constituiu-se e sua intencionalidade, como o caso da fotografia sobre o casal de escravos libertos logo abaixo. A fotografia do século XIX, um período em que se demorava mais de minutos para a sua realização, carrega de significado o ato icônico de tirar fotos, ao contrário de como conhecemos na atualidade. A vestimenta recebe a mesma proporção, bem como os sapatos, características de escravos libertos na tentativa de diferenciação.

Em suas diferentes dimensões, a fotografia evidencia um processo de tentativa de autenticidade da memória. Para Luca, a fotografia é uma poderosa ferramenta de representação social e sua análise torna-se um grande desafio no sentido de enveredar-se por áreas como a semiótica (LUCA, 2001). Para analisar esse tipo de fonte, Maurice Mouillaud também trabalha com a amplitude da percepção da imagem enquanto produtora de uma realidade social (MOUILLAUD, 2002). Assim sendo, o estudo da fotografia carrega em si alguns cuidados para não tentar transferir uma realidade social dada para outra. 
Corroborando para a percepção de que as fontes históricas também são lugares de memória, Jacques Le Goff elucida, em seus estudos, como a manipulação desses lugares ocorre e como se dá a sua utilização enquanto ferramenta de controle social (LE GOFF, 1992). O autor salienta, sobretudo, que a memória tem um potencial de orquestrar a construção da identidade de uma coletividade, o que nem sempre foi tido como positivo para o autor. É preciso pensar, dessa forma, no modus operandi em relação ao processo de manipulação dos elementos históricos.

Para a finalização do trabalho em sala de aula, a análise do terceiro documento, uma fotografia de Militão, São Paulo, de 1879. Tal documento demonstrou um rico manancial de questões sobre as práticas escravocratas e as consequências da escravidão no Brasil, tanto em seu sentido desumano, quanto em sua herança estrutural: o racismo. Em vários momentos da atividade, o racismo foi um tema muito debatido e sua faceta estrutural não pode deixar de ser questionada. Mesmo a sua massificação, na análise dos três tipos de fontes, foi fundamental para que os alunos entendessem as origens de uma prática tão desumana e tão recorrente em nossa sociedade.

Imagem 1: Foto de Militão, São Paulo, 1879.

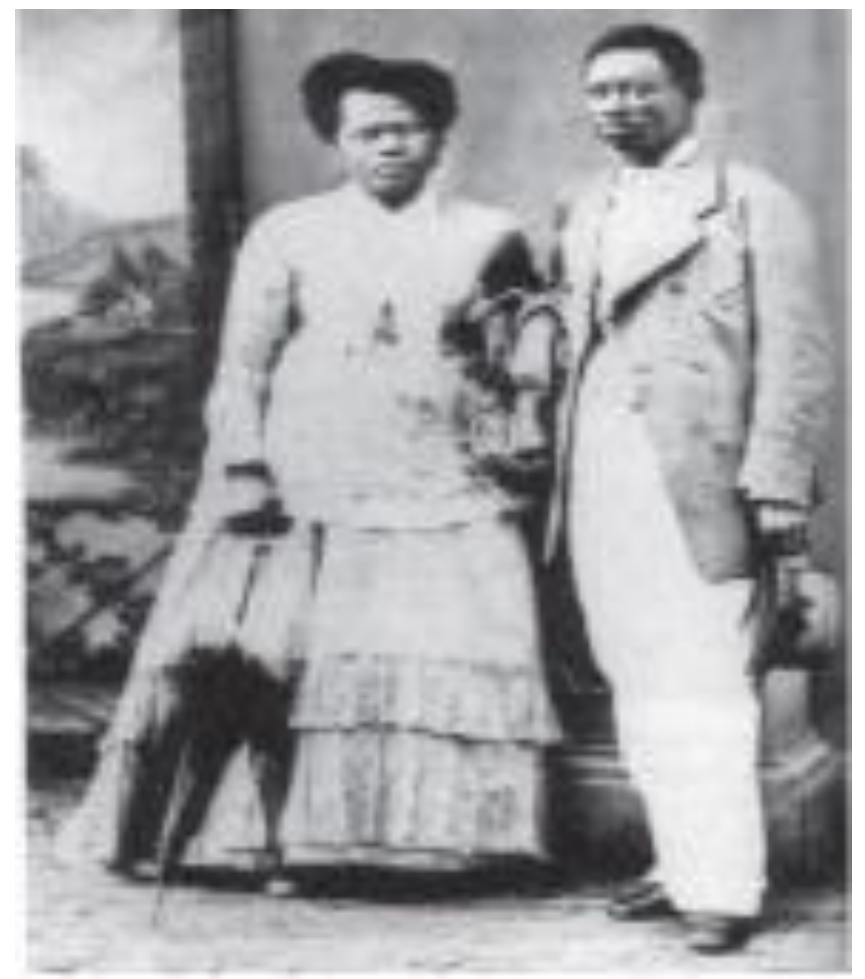

Fonte: ALENCASTRO, L. F. (org.) (1997). História da vida privada no Brasil. Império: a corte e a modernidade nacional. São Paulo: Cia. das Letras.

Para o trabalho com essa fonte, foi destacado três aspectos: 
1) Comparação entre os escravos libertos e os não libertos;

2) Ampliação do conceito de escravidão e seu movimento na sociedade imperial;

3) Abolição de escravidão e a inserção do negro na sociedade brasileira.

Para os alunos, a análise imagética ofereceu um conjunto de reflexões dentro da prática historiográfica. Mesmo que de forma simples - sem levar em consideração os percalços e fluidez da semiótica e dos vários campos de conhecimento que têm por objeto a linguagem visual - os alunos iniciaram um exercício de pensar por imagens. E a linguagem visual, constituída a partir de um sistema de representação simbólica profundamente marcada por princípios da teoria geral das representações -, abriu espaço para as possibilidades de entendimento e construção do conhecimento histórico escolar.

As competências e habilidades, equivalentes para esse ano/série, estavam ligadas ao processo de estabelecer relações entre a crise do sistema escravista e as transformações no Estado brasileiro; dominar a norma-padrão da Língua Portuguesa; interpretar dados e informações contidas em documentos históricos (SEE/SP, 2014). Nesse sentido, o material produzido pelo Estado de São Paulo, em alguns aspectos, permitiu o levantamento das habilidades e a possibilidade da busca de materiais de apoio para a construção dessa atividade. Em muitos casos, o próprio material de estudo fornecido pelo sistema do governo, na época, não tinha como pressuposto uma sistematização completa dos conteúdos e habilidades, com um trabalho direcionado de forma superficial. Mesmo diante de tamanhos desafios, os alunos conseguiram desenvolver a atividade de modo qualitativo, frente ao potencial analítico das imagens.

De imediato, os muitos alunos ficaram espantados com o processo químico de composição da fotografia no século XIX e o tempo de sua produção. Um dos alunos do $9^{\circ}$ ano C, Mateus ${ }^{12}$, partiu do pressuposto de que "no século XIX tinha muita gente burra", justamente pela inexistência tecnológica. Sua comparação estava alicerçada no fato de que tudo o que ele conhecia no século XXI era superior ao XIX. Aos poucos, foi percebendo as continuidades e rupturas, reconhecendo que alguns sacrifícios dentro do processo histórico foram realizados para o desenvolvimento da humanidade. O diálogo não foi assim tão simples, como descrevo, mas para encurtar a prosa sobre o acontecido,

\footnotetext{
${ }^{12}$ Aluno do $9^{\circ}$ ano C, sala de RCI, da Escola Estadual José Emygdio de Faria Doutor, do município de JaciSP.
} 
apenas vamos focar no fato de que ele conseguiu entender alguns elementos das transformações.

Tanto os alunos do $9^{\circ}$ ano $\mathrm{C}$, quanto os das demais salas, identificaram no ato memorialístico da fotografia uma relação com o presente e as redes sociais. Nesse sentido, no passado e no presente, o processo de construção da realidade é submetido à construção de um cenário em que a exposição deve ser eficiente em detrimento do próprio ato em si. Para a aluna Vitória, o mais importante na sociedade do século XXI seria "mostrar a própria vida" ${ }^{13}$. No século XIX, mostrar a própria condição social, indumentária e sapatos era utilizado como uma marca de distinção entre alforriados e escravizados. Tal processo, também garantia um certo status.

A partir das análises realizadas, foi de extrema importância questionar vários aspectos da escravidão no século XIX, inclusive a própria maneira de utilização da expressão escravizado. Não se trata apenas de um jogo linguístico, mas, principalmente, uma ampliação da forma que a história da população negra brasileira foi e ainda é vista, por exemplo em alguns livros didáticos. Para Mattos, é "preciso desenvolver condições para uma abordagem da história da África no mesmo nível de profundidade com que se estuda a europeia e suas influências sobre a América” (MATTOS, 2003: 135).

\section{Considerações finais}

Foi possível perceber, no trabalho com os alunos, um aproveitamento de muitas características da prática historiográfica. A capacidade de mensurar os dados, analisar as conjunturas e tecer críticas, permitiram aos alunos um desenvolvimento qualitativo de acesso às fontes.

De modo geral, a formação de base do ensino público ainda carece de análises mais aprofundadas. O conhecimento que é oferecido nas universidades públicas e nas instituições de ensino privado, frente a essa onda neoliberal que assola todo país, precisa criar um elo, uma possibilidade de diálogo eficaz com a Escola Pública. Mesmo com tantos desafios, o objeto do conhecimento não se perdeu nas práticas metodológicas, sendo capaz de fomentar inquietações apropriadas para ações em conjunto e individuais, respeitando os seus limites.

\footnotetext{
${ }^{13}$ Aluna do $9^{\circ}$ ano C, sala de RCI, da Escola Estadual José Emygdio de Faria Doutor, do município de JaciSP. 
As formas de educação, na atualidade, estão atreladas ao ideário mercadológico. Mesmo em "variantes mais humanizadas", o sistema de educacional vislumbra a propagação e confirmação do status quo na medida em que a classe detentora de capital cultural procura, em maior ou menor grau, uma coexistência contraproducente entre a libertação da humanidade e a questão meritocrática em sua perspectiva neoliberal. Descortinar o véu que assombra a humanização do ser humano, em uma sociedade colonizada pelo pensamento europeu e desigual como a brasileira, é o ponto chave para ampliar a oferta de um ensino capaz de permitir a emancipação do pensamento humano.

No que diz respeito ao Ensino de História, busca-se uma possibilidade de questionar o complexo paradoxo que se intensificou a partir das relações capitalistas: de um lado, a colonização do pensamento com a ideia de meritocracia calcada na falsa sensação de esforço individual; em contraposição, o discurso da condolência cognitiva e da construção de um mundo solidário.

Construir pontes, ao invés de muros, é a chave da mudança. É lutar cotidianamente contra a oferta do capital que promove o distanciamento das grandes utopias da humanidade - a ética, a solidariedade e, sobretudo, o contato qualitativo entre os seres humanos - e apenas valoriza o caos e a desinformação. Por isso, ensinar História em escolas públicas, na maioria das vezes, não diz respeito somente ao fato de analisar datas e contextos, mas sim de buscar incessantemente um modelo capaz de criar interações entre a perspicácia histórica, a solidariedade ao mundo sensível e autonomia intelectual.

Nos materiais oferecidos pelo governo, os chamados "caderninhos do Estado", temos uma parte significativa que diz respeito à política pública educacional implantada nas escolas da rede estadual de ensino, principalmente a partir do ano de 2008. Tratavase de um material voltado aos alunos, professores e gestores como forma de balizar a Proposta Curricular do Estado de São Paulo, hoje realidade, justamente para o cumprimento das demandas da BNCC. Mas é necessário ler criticamente tais reformas educacionais, pois há um avanço desmedido do capital em espaços que, apesar de públicos, estão a cada dia mais dominados pelo poder econômico. Inclusive, a análise desses materiais daria um bom projeto de pesquisa.

As turmas que participaram dessa atividade, em sua maioria, eram turmas com defasagens comprometedoras no que diz respeito às habilidades estruturantes para o Ensino de História. Não que o Ensino de História tenha como pressuposto a concepção de pré-requisitos, mas algumas habilidades e competências para a análise da História e historiografia são fundamentais. Inexiste a possibilidade de ser um bom aluno em 
História, ou qualquer outra disciplina, sem desenvolver com eficiência as competências leitora e escritora.

A partir da atividade, surgiram algumas oportunidades para se pensar no tipo de conteúdo e trabalho pedagógico a ser realizado com turmas, por exemplo, como a de RCI.

Nem tanto ao céu, nem tanto à terra, percebi que o trabalho pedagógico com tais características conseguiu uma proximidade maior dos alunos com o Ensino de História, longe do desejado, mas dentro da realidade de uma escola pública com problemas, contradições e estigmas.

\section{Referências bibliográficas}

ANTUNES, Ricardo (2020). Coronavírus: O trabalho sob fogo cruzado. São Paulo: Boitempo.

ARRUDA, José Jobson de Andrade (1998). Linhagens historiográficas contemporâneas por uma nova síntese histórica. Economia e Sociedade, Campinas, (10): 175-191, jun. (1980). O Brasil no comércio colonial. São Paulo: Ática.

AZEVEDO, Célia Maria Marinho (1988). Batismo da liberdade: os abolicionistas e o destino do negro. História: questões e Debates, v. 16: 38-65. . (1987). Onda negra medo branco. O negro no imaginário das elites - século XIX. Rio de Janeiro: Paz e Terra.

BLOCH, Marc (2001). Apologia da história, ou o ofício do historiador. Rio de Janeiro: Jorge Zahar.

BOURDIEU, Pierre (1987). Los três estados del capital cultural. TRADUCTOR: Monique Landesmann. VOL: AÑO 2, NÚMERO 5 FECHA: OTOÑO 1987 TEMA: EXPLORANDO EM LA UNIVERSIDAD.

BITTENCOURT, C. M. F. (1990). Patria, civilização e trebalho. O ensino de História nas escolas Paulistas. São Paulo: Loyola.

. (1993). Os confrontos de uma disciplina escolar: da história sagrada à história profana. Revista Brasileira de História, São Paulo, v.13, n.25/26: 193-221, ago. . (2018). Ensino de História, fundamentos e métodos. 5 ed. São Paulo: Cortez.

COLLARES, C. A. L. (1982). Influência da Merenda Escolar no Rendimento em Alfabetização: um Estudo Experimental. Tese de Doutorado apresentada ã Escola Pós-Graduada de Ciências Sociais da Fundação Escola de Sociologia e Política de São Paulo.

DE CERTEAU, Michel (1982). A escrita da história. Rio de Janeiro: Forense.

FREIRE, Paulo (2004). Pedagogia da autonomia: saberes necessários a prática educativa. São Paulo: Paz e Terra. (1981). Pedagogia do Oprimido. 9 ed. Rio de Janeiro. Editora Paz e Terra.

GARDNER, Howard (1994). Estruturas da mente. A Teoria das Inteligências Múltiplas. Porto Alegre. Artes Médicas. 
HOBSBAWM, E. (2007). Globalização, democracia e terrorismo. Tradução de José Viegas. São Paulo: Companhia das Letras.

LUCIANO, Tiago Ricardo (2016). Orientações para o Ensino de História da África para estudantes do Ensino Médio. 35f. Orientador: Macioniro Celeste Filho Produto educacional elaborado como parte das exigências do Mestrado Profissional em Docência para a Educação Básica da Faculdade de Ciências, UNESP, Bauru.

LE GOFF, Jacques (1992). História e Memória. Tradução Bernardo Leitão. Campinas, SP: Ed. Unicamp.

LIBÂNEO, José Carlos (1994). Didática. São Paulo: Cortez.

MACHADO, Maria Helena Pereira Toledo (2004). Sendo cativo nas ruas: a escravidão urbana na cidade de São Paulo. In: PORTA, Paula (org.). História da Cidade de São Paulo: A Cidade no Império, 1823-1889. V. 2. São Paulo: Paz e Terra.

MARTINS, J. de S. (2002). A sociedade vista do abismo: novos estudos sobre exclusão, pobreza e classes sociais. Petrópolis, RJ: Vozes.

MATTOS, Hebe Maria (2013). O ensino de História e a luta contra a discriminação racial no Brasil. In: ABREU, Martha; SOIHET, Rachel (orgs.). Ensino de História: conceitos, temáticas e metodologia. Rio de Janeiro: Casa da Palavra.

MATOSO, José (1988). A escrita da história - teoria e métodos. Lisboa: editorial Estampa.

MÉZÁROS, Stiván (2005). A Educação Para Além do Capital. Tradução e notas: TAVARES, Isa. São Paulo: Boitempo.

MONTEIRO. Ana Maria (2007). Professores de História entre Saberes e Práticas. RJ, Mauad.

MOUILLAUD, Maurice (2002). O jornal: da forma ao sentido. In: PORTO, Sergio Dayrell Porto (org). Brasília: editora Universidade de Brasília.

PIAGET, J. (1994). O Juízo Moral na Criança. São Paulo: Summus. (1999). Seis Estudos de Psicologia. 24 ed. Rio de Janeiro: Forense Universitária.

PIAGET, J. (1970 [1969]). Psicologia e Pedagogia. Rio de Janeiro: ForenseUniversitária, 1970

PINSKY, Carla Bassanezi; LUCA, Tania Regina (2011). O historiador e suas fontes. São Paulo: Contexto.

PORTELLLI, Alessandro (1997). O que faz a história oral diferente. Tradução: Maria Therezinha Janine Ribeiro. Revisão técnica: Dea Ribeiro Fanelon. Proj. História, São Paulo (14): 25-39, fev.

QUIJANO, Aníbal (2005). Colonialidade do Poder, Eurocentrismo e América Latina. In: Colonialidade do Saber: eurocentrismo e ciências sociais, Perspectivas latinoamericanas. Buenos Aires: CLACSO.

PLATÃO (2000). A República. Tradução Carlos Alberto Nunes. Belém: EDUFPA.

RICOUER, Paul (2007). A memória, a história, o esquecimento. Campinas: Edunicamp.

RUIZ, Rafael (2007). Novas formas de abordar o Ensino de História. In KARNAL, Leandro (org.). História em sala de aula: conceitos, práticas e propostas. SP: contexto.

SANTOS, Milton (2000). POR UMA OUTRA GLOBALIZAÇÃO: do pensamento único à consciência universal. Rio de Janeiro: Record.

SCHMIDT, Maria Auxiliadora e CAINELLI,Marlene (2009). Ensinar História. SP: Scipione.

SEE/SP (2014). Secretaria da Educação do Estado de São Paulo. Caderno do professor. (História). São Paulo: IMESP. (2014). Caderno do aluno, (História). São Paulo: IMESP. (s.d.). São Paulo Faz Escola. In: www.educacao.sp.gov.br. 
. (2008). Proposta Curricular do Estado de São Paulo: História.

- (2012). Currículo do Estado de São Paulo: Ciências Humanas e suas Tecnologias.

Secretaria da Educação; coordenação geral, Maria Inês Fini; coordenação de área,

Paulo Miceli. Ed. atual. São Paulo: SE.

Artigo recebido em 14 de março de 2021.

Aprovado em 10 de novembro de 2021.

DOI: 10.12957/intellectus.2021.58405 